\title{
A Sense of Things to Come: Future Research Directions in Sensory Marketing
}

\author{
Ryan S. Elder, Nilufer Z. Aydinoglu, Victor Barger, Cindy Caldara, HaeEun Chun, Chan Jean Lee, \\ Gina S. Mohr, and Antonios Stamatogiannakis
}

The exciting exploration on sensory marketing presented in this book is just the foundation upon which to build future research. There are myriad unexplored questions and innumerable directions in which to take this research. Our goal in this chapter is not to provide an exhaustive array of these future directions, but rather to stimulate the reader into exploring new ideas. We present possible future directions for each sense individually (vision, audition, smell, touch, taste), and conclude with ideas for future research addressing the interplay among multiple senses within consumer behavior.

\section{Vision}

Although vision to date is the most studied sensory domain within consumer research, there are still numerous future directions to explore. We present a few directions here, including the impact of vision on sensory imagery, the impact of color on consumer behavior, as well as the consequences of visual salience.

Imagery is defined as a process by which sensory information is represented in working memory (Maclnnis \& Price, 1987). In the consumer behavior literature, visual imagery has been shown to assist in processing product information and in facilitating memory and persuasion (e.g., Alesandrini \& Sheikh, 1983; Bone \& Ellen, 1992; McGill \& Anand, 1989). Conversely, a lack of imagery-facilitating visual input may have negative effects on persuasion (Kisielius \& Sternthal, 1984; Petrova \& Cialdini, 2005). For example, when a product or ad is not presented in a visually vivid way, this impairs the fluency of consumption imagery, or the ease with which consumers can generate imagery of the consumption experience, leading to a negative effect of imagery appeals.

Research on imagery in consumer behavior and psychology has predominantly focused on vision. Prior literature neglects to address how the different modalities interact to create a more 
complete image beyond visual. Supplementing visual cues with other sensory cues may enhance the influence of consumer imagery on perceptions, attitudes, and behaviors. That is, even under conditions where the visual information presented to consumers is insufficient in generating visual imagery, other sensory input may enhance the generation of visual imagery. For example, even when the visual information in a print ad is not vivid enough, coupling the ad with a touch, smell, or sound element may transfer the richness of one modality to another (i.e., vision), thereby enhancing one's imagined visual experience. Conversely, it is likely that a visual input will contribute to the ease of generating imagery of other sensory modalities or enhancing the intensity of experiencing them. The consequences of visual imagery may be greatly enhanced by the addition of other sensory inputs.

Another underexplored aspect of vision is color. Studies on color have provided evidence as to how certain colors in ads are more likely to lead to positive attitudes (e.g., Gorn, Chattopadhyay, Yi, \& Dahl, 1997). However, the explication of the process that leads to such attitudinal changes has been left largely unexplored. We need to establish boundary conditions as to when certain colors are more preferred and why. We also need to investigate how consumers react to combination of colors (e.g., red and white) and combination of colors and shapes (e.g., red and round vs. red and rectangle), as the visual cues consumers encounter in the market are mixtures of multiple aspects. Another interesting question is how visual cues interact with consumer emotions. Would color or shape preference change depending on how consumers feel? For example, would some colors or shapes be more preferred when consumers are happy (vs. sad)? More broadly, examining emotion as it relates to sensory processing may serve to explain the vast individual heterogeneity in response to visual and other sensory cues.

Finally, the role of salience of visual cues has produced exciting results such as biases in perception of volume (Raghubir \& Krishna, 1999; Wansink \& Van Ittersum, 2003), distances (Raghubir \& Krishna, 1996), taste (Hoegg \& Alba, 2007), and consequently product evaluations and choices. We expect selective attention to salient visual cues to be a continuously rich source of research. One aspect of consumer behavior we expect to be particularly affected is information search. As practitioners recognize the importance of quick conveyance of information, we see a shift from verbal to visual displays of information. The consequences of such a strategy should be more fully explored; some recent research has begun to address these issues. For example, online product ratings, such as 5-star customer ratings on Amazon, com, are visual cues through which companies and consumers communicate. If a particular star rating (e.g., 5-star) is more salient than other ratings (e.g., 1-star), the higher attention to the salient rating could bias how consumers process other star ratings and how consumers make decisions based on online ratings (Lee \& Raghubir, 2008). Understanding how these 
visual biases are formed and the confidence with which they are held will allow us to improve the information search process for consumers.

\section{Audition}

Audition (like smell, but unlike vision, touch, and taste) is a sense that requires no effort to operate. People have no control over the auditory stimuli they perceive, although they have some control over which stimulus they are attending to. This nonvoluntary perception of sounds can make the fit (congruence) of an auditory stimulus (e.g., music) with either the environment (e.g., a store) or other auditory stimuli (e.g., the next music track) problematic. In large department stores, supermarkets, bars, restaurants, and other locations, sound incongruence cannot be avoided. If the same music is played everywhere in the store, there will be some parts of the store where the music will not fit. If different music is played in different parts, then the different music themes are very likely to not fit with one another. Considering that in general, music congruence has been found to have positive effects for product and ad evaluations (see Peck \& Childers, 2008), this raises three important questions. First, the marketing literature has not yet addressed the effects (if any) of incongruence between sequential or simultaneous auditory stimuli. Second, in cases where incongruence is unavoidable, should a store opt for one or the other form of incongruence? Third, the marketing literature should identify boundary conditions for the positive effects of sound congruence in the same way it has identified boundary conditions for desirable properties of visual stimuli, such as symmetry and unity (Stamatogiannakis, Chattopadhyay, \& Gorn, forthcoming).

Another issue that research so far has not resolved is a possible confound of music familiarity and pleasantness. The effects of the two have been found to be very similar: Perceived time duration is longest for positively valenced music (Kellaris \& Kent, 1992), but the same holds for more familiar music (Yalch \& Spangenberg, 2000). Furthermore, the effects of music on mood and on product evaluation (Gorn, Goldberg, \& Basu, 1993) might be partially explained by music familiarity. We are not aware of any study that orthogonally manipulates music familiarity and music valence, although researchers have identified them as two separate moderators of music effects (Bruner, 1990). Such studies are necessary in order to understand whether well-grounded effects of music valence on mood can be attributed to valence alone or whether music familiarity can explain part of the effects. An additional point regarding auditory effects on the perception of time arises from recent research. When resources required match resources available, people perceived that more time has passed than when available and required resources do not match (Mantel \& Kellaris, 2003). Assuming that familiar and pleasant music requires 
less resources to be processed, then the results of the studies showing that pleasant and familiar music leads to longer time estimates might not hold in situations when one has plenty available resources (e.g., in a relaxing dinner).

Another field of research in audition is the sounds that are inseparable from product usage, for example, the sound a car door makes when it shuts, the sound a DVD player makes when it opens, or even the sound an electronic device (e.g., an air conditioner or a car alarm) makes when switched on. It is possible that through phonetic symbolism people infer product attributes from these sounds, in the same way they do from the sound of a brand name (Yorkston \& Menon, 2004).

A final point that merits attention is if and how speech can create inferences for a product. Chattopadhyay, Dahl, Ritchie, and Shahin (2003) have shown that when a male speaks, then low pitch and a little fast syllable speed produce the best responses to the speech. However, more qualitative insights might be useful: Can the accent (or the pitch or the speed) of the speaker in an ad (or the origin and the tempo of the music) imply the product's possession of certain characteristics or act as a quality signal? Additionally, are consumers cognizant of the sources of these inferences?

\section{Smell}

In the early 1990s, Bone and Jantrania (1992) proposed that "the sense of smell has for the most part been overlooked by market researchers" (p. 289). However, in the past two decades, researchers across several disciplines have shown a profound interest in the topic of olfaction and have produced foundational research in the area. We propose here additional directions to explore in order to more fully understand the role smell plays in consumer behavior. Specifically, we direct further attention to the role of scent congruence, the generation of semantic meanings of scents, the impact of attention, as well as highlight the emergence of new methodologies to study smell.

The presence of a scent is generally acknowledged as having a positive impact on consumer attitudes, in both ambient form, such as in stores and other environments, or in a more direct form, such as those infused in products. Among the cognitive moderators potentially involved in these effects, perceived congruence is the most frequently reviewed one. In general it is defined as a contextual fit between the scent and the product category (Bosmans, 2006; Mitchell, Kahn, \& Knasko, 1995; Morrin \& Ratneshwar, 2003; Spangenberg, Sprott, Grohmann, \& Tracy, 2006). The effects of congruence are directionally shared among the studies claiming congruence has a more positive impact on memory and evaluation than incongruence. However, research should focus on specifying the types of positive 
impacts that scents have. For example, do scents result in greater attachment to the product as more sensory modalities are stimulated, and how does congruence affect these consequences?

Congruence, as mentioned, plays a significant role in determining the impact of scent on consumer perceptions and attitudes. However, the reasons why a scent is perceived as congruent are not always clear. It may be posited that scents hold shared semantic meanings that lead to a perception of congruence between a smell and an object. Brand and Millot (2001) argue that the explanation of gender differences in olfaction may be related to the fact that olfactory stimuli can have a greater meaning for one gender than for the other. The types and relative importance of scent meanings and the way in which individuals learn them should receive more attention. Cultural or social meanings attributed to scents may be derived largely from experience, in some form of a conditioning framework. It would be useful to identify the sources of such conditioning, establish typologies for them, pay attention to the way they are processed by individuals, and determine whether there is a way to replicate this learning process in a consumer context.

Another variable that should be more actively considered is the impact of attention in processing scents. Recently, Zelano and colleagues (2005) highlighted the role of different levels of attention on scent perception at a neural level. One of the main characteristics of a scent is that it can be processed preattentively (Davies, Kooijman, \& Ward, 2003). As such, it would be useful to determine whether the presence of scents has to be consciously perceived by consumers to positively affect the target variable (e.g., store environment perceptions or product evaluation). Indeed, if the process occurs largely below consciousness, then a large responsibility of the marketer is to create the aforementioned semantic associations between the product and scent in order for the associations to be operative.

The study of individual differences should also constitute a further step in smell research. Anatomic and physiologic differences (gender, age, genetics) have been documented (Brand \& Millot, 2001), and it is likely that other individual differences exist that affect scent perceptions. For example, do individuals differ in their need for smell (similar to the need for touch; Peck \& Childers, 2003a), the centrality of smells in their lives, or in their emotional reaction to smells? Wrzesniewski, McCauley, and Rozin (1999) have developed a scale measuring individual differences in the affective impact of odors on places, objects, and persons, demonstrating that differences other than biologic ones influence scent perception. Among others, one promising direction for future research would be to develop a general scale measuring the susceptibility of an individual to using scent as an input for decisions and evaluations. 
Finally, recent advances in physiological instrumentation provide an opportunity to capture process beyond self-report measures. Brain imaging (e.g., functional magnetic resonance imaging; Zelano et al., 2005) and other psychophysiological measures such as galvanic skin response, heart rate, and blood pressure all provide levels of sensory stimulation and activation that should prove useful in more fully understanding the mysteries of scents within marketing.

\section{Touch}

Touch research in marketing is, in many respects, still in its infancy. Although advances have been made in recent years (see Chapter 2), there are still numerous avenues for future research. In this section, we outline three such avenues that hold great promise. First, focus should be given to ways of motivating consumers to touch. Second, researchers should examine how consumers interpret stimuli. Finally, researchers can explore alternatives to direct physical contact that result in similar consequences.

Touch is rarely ambient, meaning that consumers must make an effort to experience haptic stimuli. As such, marketers need to understand the motivation for touch before they can reap the benefits, benefits that are, as revealed in Chapter 2 of this book, significant: touch enhances the purchase experience (Peck \& Childers, 2003a), leads to greater confidence in product judgments (Peck \& Childers, 2003a), and increases the amount consumers are willing to pay for products (Peck \& Shu, 2009).

Three aspects of the purchase experience determine motivation to touch: the product, the consumer, and the environment. We know from prior research (Klatzky \& Lederman, 1992, 1993) that objects differ on material properties, such as texture, softness, and weight, and that touch enables us to sense these differences more effectively than other senses. More recently, Peck and Wiggins (2006) showed that material properties of objects influence whether haptic stimuli are perceived as pleasant or unpleasant. This link between material properties and hedonic touch remains relatively unexplored, however. What causes a material property to be perceived as pleasant? Are there particular textures or shapes that are universally pleasing? How can marketers leverage the material properties of products to induce touch?

Of course, material properties alone cannot explain why some consumers touch when others do not. To investigate this, Peck and Childers (2003a) designed a scale that measures individual preference for touch information. The availability of this scale has opened numerous opportunities for further research on touch. For example, do individuals differ in motivation to touch by demographics such as 
gender and age? What impact does culture have on motivation to touch? How does the ability to differentiate haptic attributes vary across individuals? We do know that sensitivity to touch declines with age (Stevens \& Patterson, 1995; Thornbury \& Mistretta, 1981), but what are the implications for marketing?

Beyond the level of the product and the individual, situational factors also influence motivation to touch. Changes in the retail environment, for example, can have a substantial impact on the willingness of consumers to touch products, as shown by Peck and Childers (2006). Social influence may also play a role in motivating touch. For example, if a consumer sees someone touch an object, he or she may view that as a sign that touching is acceptable. Moreover, the observation may engender curiosity and encourage firsthand experience. Of course, he or she may also fear product contagion (Morales \& Fitzsimons, 2007); whether observing another individual touch a product has a positive or negative effect on consumer affect and attitudes is open to investigation.

Once a consumer is induced to touch, consideration turns to how he or she interprets the haptic stimuli. This is likely a complex function of product attributes, individual characteristics, and situational factors. Consider, for example, the interaction between the material properties of an object and ambient temperature. First, the diagnosticity of touch changes with temperature; that is, the same material feels different at different temperatures. Second, the temperature of the object is subject to interpretation. For instance, warmth in an item of clothing may indicate that the item had just been tried on, raising concerns of product contagion. Finally, there are individual differences in ability to differentiate haptic stimuli. The ramifications extend to all aspects of marketing, from product design to retail display.

Unfortunately, touch is not feasible in all consumption contexts. The most notable is online shopping, where consumers must rely entirely on visual stimuli. It is not surprising, then, that consumers who prefer tactile input are less likely to purchase online (Citrin, Stem, Spangenberg, \& Clark, 2003). The problem is exacerbated in product categories where touch is particularly diagnostic, such as clothing and bedding. Alternatives to physical touch are thus of great practical interest. Although verbal descriptions may help (e.g., inferring softness from thread count), such descriptions do not satisfy the need for autotelic touch (Peck \& Childers, 2003b). One promising alternative is haptic imagery (Peck \& Barger, 2008), which may act as a surrogate for touch; further research in this area is needed, however. 


\section{Taste}

As noted in Chapter 18 in this volume, the sense of taste has received sparse attention within the consumer behavior literature. However, extant literature addressing taste does provide a solid foundation from which to build future research. Attention to three specific areas in taste and consumer behavior may result in substantial progress of this exciting domain. First, we recommend devoting further attention to the interplay of affect and cognition in taste experiences. Second, we propose that future research focus more deeply on the conscious and unconscious determinants of taste perception, including the perceptual effects of extrinsic and intrinsic cues. Finally, research should address individual differences in taste perceptions, such as food expertise and an individuals ability to generate sensory imagery.

Food is an essential component of human existence, with much of our daily efforts devoted to ensuring that we have sufficient amounts for our needs. However, beyond this subsistence perspective, food, and more specifically the sense of taste, provides us with some of our greatest pleasures. Prior literature on the topic of affect and cognition, as it relates to taste, suggests that many taste experiences are primarily affective, with cognitive or informational components muting enjoyment during consumption (Nowlis \& Shiv, 2005; Shiv \& Fedorikhin, 1999; Shiv \& Nowlis, 2004). For example, Nowlis and Shiv (2005) show that reducing attention to informational components enhances taste perceptions and consumption enjoyment of chocolate and also leads to greater selection of the more affective option within a choice set.

In general, taste perceptions tend to be affectively driven, with more attention to sensory cues leading to heightened affective responses. However, with the current health-conscious focus, particularly within the United States, the enjoyment of food may have several negative consequences, leading many to believe that4 eating is almost as dangerous as not eating" (Rozin, Fischler, Imada, Sarubin, \& Wrzesniewski, 1999, p. 164). Therefore, an underlying question is to what extent marketers and other professionals can balance this interplay between affect and cognition to increase subsequent enjoyment of healthy food items. A similar question to be addressed is what attributes of the taste experience make the focus primarily cognitive rather than affective. Finally, as prior literature suggests that affective components function more automatically and cognitive inputs function in a more deliberative manner (Compeau, Grewal, \& Monroe, 1998; Shiv \& Fedorikhin, 1999), is there a way to enable cognitive components to be processed more automatically, thereby reducing the detrimental impact of negative cues? 
Within cognitive psychology, several researchers have posited that most of our lives are driven by automatic processes, outside of our own consciousness (Bargh, 2002; Bargh \& Chartrand, 1999). The environment and other extrinsic cues outside of consciousness influence perceptions and even behaviors. Understanding the unconscious and conscious determinants of taste perceptions, including the aforementioned affective and cognitive inputs as well as intrinsic and extrinsic cues, is a second fruitful domain to explore.

Intrinsic cues such as appearance, tactile properties, smell, and other sensory characteristics of the food item may be operative at both the conscious and unconscious levels. Therefore, manipulating the level of consciousness devoted to these intrinsic cues may affect subsequent taste perceptions. Researchers have addressed the impact of additional intrinsic cues on taste perceptions such as product color (DuBose, Cardello, \& Mailer, 1980; Hoegg \& Alba, 2007), product smell (Prescott, Johnstone, \& Francis, 2004), and product texture (Christensen, 1980); however, future research should determine to what extent these intrinsic cues act automatically and below consciousness or whether they require cognitive elaboration and consciousness. For instance, does the congruity of the intrinsic cues with expectations determine whether or not further cognitive resources are expended and consequently affect how sensory characteristics are attended to? Determining when intrinsic product cues have the most prominent impact on taste perceptions will aid in understanding the role of extrinsic cues.

Extrinsic cues, such as advertising (Elder \& Krishna, 2010), brand name (Allison \& Uhl, 1964; Hoegg \& Alba, 2007), product ingredients (Lee, Frederick, \& Ariely, 2006; Raghunathan, Naylor, \& Hoyer, 2006), and even product packaging (Krishna \& Morrin, 2008), also operate at conscious and unconscious levels on taste perceptions. The underlying process with which these extrinsic cues are operative remains to be fully addressed. One future area of research could determine to what extent, and at what level of consciousness, expectations influence perceptions. Lee et al. (2006) introduce a negatively valenced ingredient for beer (balsamic vinegar) both before and after consumption and show that the introduction of the ingredient before consumption altered the perceptual experience, whereas the introduction of the ingredient after consumption had little effect on taste perceptions. This research shows the power of expectations in affecting the experience itself, not merely perceptions of the experience, but fails to address the consciousness of such an effect. The general field of sensory marketing, and in particular taste marketing, will largely benefit from a focus on the conscious and subconscious effects of intrinsic and extrinsic cues.

The third and final recommendation for future research within taste marketing is to focus on individual differences. What characteristics of individuals make their taste experiences susceptible to 
marketing actions? One obvious area for exploration is the individual s level of expertise within the food domain. Such differences in expertise have been shown to have a discernible impact on taste perceptions, particularly in respect to an individuals focus during a consumption experience. Specifically, experts are more likely to focus on automatic, affective components of the consumption experience rather than the more deliberate, cognitive components (Nowlis \& Shiv, 2005). Therefore, experts may not pay as much attention to the marketing communications, but rather focus on the sensory experience of eating. Other individual differences, such as the ability to imagine taste experiences, could potentially moderate the effect of marketing on taste perceptions. These individual-level moderators, as well as many more, can provide insight into when and how marketing affects taste.

\section{Multisensory}

Much of the literature on consumer sensory processing examines sensory modalities singularly. Yet, consumers rarely process information in this way. Rather, we know that information is perceived and processed in multiple sensory modalities. For example, somebody who is choosing among sweaters may use both visual (color) and haptic (texture) cues to arrive at a preference. Moreover, marketers make appeals to consumers in many sensory modalities in order to attract attention, to give information, or to accentuate product features (e.g., a visual cue of a lemon to instantiate the fragrance in a cleaning product). Recognizing the significance of the multisensory nature of perception and information processing, some marketing scholars have begun to direct attention toward the interplay between the senses. For example, intersensory effects and synergies between vision and taste (Hoegg \& Alba, 2007), vision and touch (Raghubir \& Krishna, 1999), touch and taste (Krishna \& Morrin, 2008), and sound and taste (Zampini \& Spence, 2004) have begun to be explored. However, considering the complex nature of such multisensory processing and its significant effect on consumer perception and behavior, we believe that more systematic inquiry is needed to expand our understanding of this complex, yet natural, way in which consumers interact with their surroundings.

It is important to understand multiple-sensory interactions because cross-modal cues may facilitate or interfere with one another in how they affect consumers1 perceptions, attitudes, and preferences. For example, does the preference for a fragranced product change as a function of the additional sensory cues that are provided? In studying such joint effects, attention should be directed toward the different roles played by the different modalities of cues and the processes by which they affect outcomes of interest. Zampini and Spence (2004), for instance, study how the auditory cues produced during the biting action of potato chips affect the perception of crispness and staleness of the 
chips, which is a very important attribute for the product category. Hoegg and Alba (2007) investigate how color differences in orange juice samples affect taste discrimination. Even in these instances, where such cues might initially be thought of as secondary (i.e., auditory for potato chips and visual for orange juice), we see their significant role in affecting consumer judgment and consequently preference. Identification of such specific roles and relationships would shed light on the processes leading to the desired response from consumers.

Another reason that further investigation into multiple-sensory interactions is important is that cross-modal cues may affect consumer memories differently. The interactive effects of modality on memory can be investigated at both encoding and retrieval. For example, a consumer watching an advertisement may encode a brand name with an auditory cue (song) and a visual cue (logo). However, each cue may differentially facilitate (or inhibit) the encoding and retrieval of the brand name or brand concept. This effect may be further moderated by congruity among the cues or the familiarity of these cues. Existing literature on congruity effects in other domains of consumer behavior research suggest that incongruent cues can enhance memory for a product (Lee \& Mason, 1999; Unnava, Agarwal, \& Haugtvedt, 1996). However, to our knowledge there has been little research that examines how these congruity effects extend into multisensory interactions.

Moreover, studying the interplay between sensory cues should not be blind to contextual and individual contingencies. There might be important differences among consumers in their inclination to use a certain modality in their perceptions and judgments. Krishna and Morrin (2008), for example, show that different levels of "need for touch" (Peck \& Childers, 2003a) result in different effects within the context of the interplay of vision and touch. As mentioned earlier, the development of such respondent-level scales is another promising venue for research, as it will enhance our understanding of consumers, giving more weight to certain modalities while neglecting others, when there is opportunity to use different sensory cues. The same is true for the moderating effects of different contextual variables; Grohmann, Spangenberg, and Sprott (2007), for instance, show that touch matters more for high-quality products. Studying these moderating effects would provide more information to the marketer about the relative importance of different modalities of cues in designing an offer or in formulating communication.

\section{Conclusions}

Although not representing an exhaustive list of possible future directions, it is our intention that the preceding discussion on sensory marketing research areas would excite and inspire the reader. This 
nascent field has much promise, particularly while garnering the scholarly attention of top researchers. Hopefully this chapter has given the reader a sense of things to come.

\section{References}

Alesandrini, K., \& Sheikh, A. (1983). Research on imagery: Applications to advertising. In A. Sheikh (Ed.), Imagery: Current theory research and application (pp. 535-556). New York: John Wiley.

Allison, R. I., \& Uhl, K. R (1964). Influence of beer brand identification on taste perception. Journal of Marketing Research, 1(3), 36-39.

Bargh, J. A. (2002). Losing consciousness: Automatic influences on consumer judgment, behavior, and motivation. Journal of Consumer Research, 29(2), 280-285.

Bargh, J. A., \& Chartrand, T. L. (1999). The unbearable automaticity of being. American Psychologist, $54(7), 462-479$.

Bone, R F., \& Ellen, R S. (1992). The generation and consequences of communication- evoked imagery. Journal of Consumer Research, 19(1), 93-104.

Bone, P. F., \& Jantrania, S. (1992). Olfaction as a cue for product quality. Marketing Letters, 3(3), 289296.

Bosmans, A, (2006). Scents and sensibility: When do (in)congruent ambient scents influence product evaluations? Journal of Marketing, 70(3), 32-43.

Brand, G., \& Millot, J. L. (2001). Sex differences in human olfaction: Between evidence and enigma. Quarterly Journal of Experimental Psychology, 54(3), 259-270.

Bruner II, G. C. (1990). Music, mood, and marketing. Journal of Marketing, 54(4), 94-104.

Chattopadhyay, A., Dahl, D. W., Ritchie, R. J. B., \& Shahin, K. N. (2003). Hearing voices: The impact of announcer speech characteristics on consumer response to broadcast advertising. Journal of Consumer Psychology, 13(3), 198-204.

Christensen, C. M. (1980). Effects of solution viscosity on perceived saltiness and sweetness. Perception and Psychophysics, 28(4), 347-353.

Citrin, A. V., Stem, D. E., Spangenberg, E. R., \& Clark, M. J. (2003). Consumer need for tactile input: An Internet retailing challenge. Journal of Business Research, 56(11), 915-922.

Compeau, L.D., Grewal, D., \& Monroe, K. (1998). Role of prior affect and sensory cues on consumers affective and cognitive responses and overall perceptions of quality. Journal of Business Research, 42(3), 295-308. 
Davies, B. J., Kooijman, D., \& Ward, P. (2003). The sweet smell of success: Olfaction in retailing. Journal of Marketing Management, 19(5-6), 611-627.

DuBose, C. N., Cardello, A. V., \& Mailer, O. (1980). Effects of colorants and flavorants on identification, perceived flavor intensity, and hedonic quality of fruit-flavored beverages and cake. Journal of Food Science, 45(5), 1393-1399.

Elder, R. S. \& Krishna A. (2010). The effects of advertising copy on sensory thoughts and perceived taste. Journal of Consumer Research, 36.

Gorn, G. J., Chattopadhyay, A., Yi, T., \& Dahl, D.W. (1997). Effects of color as an executional cue in advertising: They're in the shade. Management Science, 43(10), 1387-1400.

Gorn, G. J., Goldberg, M. E., \& Basu, K. (1993). Mood, awareness, and product evaluation. Journal of Consumer Psychology, 2(3), 237-256.

Grohmann, B., Spangenberg, E. R., \& Sprott, D. E. (2007). The influence of tactile input on the evaluation of retail product offerings. Journal of Retailing, 83(2), 237-245.

Hoegg, J., \& Alba, J. W. (2007). Taste perception: More than meets the tongue. Journal of Consumer Research, 33(4), 490-498.

Kellaris, J. J., \& Kent, R. J. (1992). The influence of music on consumers temporal perceptions: Does time fly when you're having fun? Journal of Consumer Psychology, 1(4), 365-376.

Kisielius, J., \& Sternthal, B. (1984). Detecting and explaining vividness effects in attitudinal judgments. Journal of Marketing Research, 21(1), 54-64.

Klatzky, R. L., \& Lederman, S. J. (1992). Stages of manual exploration in haptic object identification. Perception and Psychophysics, 52(6), 661-670.

Klatzky, R. L., \& Lederman, S. J. (1993). Toward a computational model of constraint- driven exploration and haptic object identification. Perception, 22(5), 597-621.

Krishna, A., \& Morrin, M. (2008). Does touch affect taste? The perceptual transfer of product container haptic cues. Journal of Consumer Research, 34(6), 807-818.

Lee, C. J. \& Raghubir, R (2008). Psychological values of ratings. Working paper.

Lee, L., Frederick, S., \& Ariely, D. (2006). Try it, you'll like it: The influence of expectation, consumption, and revelation on preferences for beer. Psychological Science, 17(12), 1054-1058.

Lee, Y. H., \& Mason, C. (1999). Responses to information incongruency in advertising: The role of expectancy, relevancy, and humor. Journal of Consumer Research, 26(2), 156-169.

Maclnnis, D.J., \& Price, L. (1987). The role of imagery in information processing: Review and extensions. Journal of Consumer Research, 13(4), 473-491. 
Mantel, S. P., \& Kellaris, J. J. (2003). Cognitive determinants of consumers time perceptions: The impact of resources required and available. Journal of Consumer Research, 29(4), 531-538.

McGill, A. L„, \& Anand, P. (1989). The effect of vivid attributes on the evaluation of alternatives: The role of differential attention and cognitive elaboration. Journal of Consumer Research, 16(2), 188196.

Mitchell, D. J., Kahn, B. E., \& Knasko, S. C. (1995). There's something in the air: Effects of congruent or incongruent ambient odor on consumer decision making. Journal of Consumer Research, 22(2), 229-238.

Morales, A. C., \& Fitzsimons, G. J. (2007). Product contagion: Changing consumer evaluations through physical contact with "disgusting" products. Journal of Marketing Research, 44(2), 272-283.

Morrin, M., \& Ratneshwar, S. (2003). Does it make sense to use scents to enhance brand memory? Journal of Marketing Research, 40(1), 10-25.

Nowlis, S. M., \& Shiv, B. (2005). The influence of consumer distractions on the effectiveness of foodsampling programs. Journal of Marketing Research, 42(2), 157-168.

Peck, J., \& Barger, V. A. (2008). In search of a surrogate for touch: The effect of haptic imagery on psychological ownership and object valuation. Working paper.

Peck, J. \& Childers, T. L. (2003a). Individual differences in haptic information processing: The 'Need for Touch' scale. Journal of Consumer Research, 30(3), 430-442.

Peck, J., \& Childers, T. L. (2003b). To have and to hold: The influence of haptic information on product judgments. Journal of Marketing, 67(2), 35-48.

Peck, J., \& Childers, T. L. (2006). If I touch it I have to have it: Individual and environmental influences on impulse purchasing. Journal of Business Research, 59(6), 765-769.

Peck, J., \& Childers, T. L. (2008). If it tastes, smells, sounds, and feels like a duck, then it must be a ...: Effects of sensory factors on consumer behaviors. In C. P Haugtvedt, P. M. Herr, \& F. R. Kardes (Eds.), Handbook of consumer psychology (pp. 193-219). New York: Psychology Press.

Peck, J, \& Shu S. (2009). The effect of mere touch on perceived ownership. Journal of Consumer Research, (36).

Peck, J., \& Wiggins, J. J. (2006). It just feels good: Consumers affective response to touch and its influence on attitudes and behavior. Journal of Marketing 70(4), 56-69.

Petrova, P. K., \& Cialdini, R. B. (2005). Fluency of consumption imagery and the backfire effects of imagery appeals. Journal of Consumer Research, 32(3), 442-452. 
Prescott, J., Johnstone, V., \& Francis, J. (2004). Odor-taste interactions: Effects of attentional strategies during exposure. Chemical Senses, 29(4), 331-340.

Raghubir, P., \& Krishna, A. (1996). As the crow flies: Bias in consumers' map-based distance judgments. Journal of Consumer Research, 23(1), 26-39.

Raghubir, P., \& Krishna, A. (1999). Vital dimensions in volume perception: Can the eye fool the stomach? Journal of Marketing Research, 36(6), 313-326.

Raghunathan, R., Naylor, R. W., \& Hoyer, W. D. (2006). The unhealthy = tasty intuition and its effects on taste inferences, enjoyment, and choice of food products. Journal of Marketing, 70(4), 170-184.

Rozin, P., Fischler, C., Imada, S., Sarubin, A., \& Wrzesniewski, A. (1999). Attitudes to food and the role of food in life in the U.S.A., Japan, Flemish Belgium and France: Possible implications for the diethealth debate. Appetite, 33(2), 163-180.

Shiv, B., \& Fedorikhin, A. (1999). Heart and mind in conflict: The interplay of affect and cognition in consumer decision making. Journal of Consumer Research, 26(3), 278-292.

Shiv, B, \& Nowlis, S. M. (2004). The effect of distractions while tasting a food sample: The interplay of informational and affective components in subsequent choice. Journal of Consumer Research, 31(3), 599-608.

Spangenberg, E. R., Sprott, D. E., Grohmann, B., \& Tracy, D. L. (2006). Gender-congruent ambient scent influences on approach and avoidance behaviors in a retail store. Journal of Business Research, 59(12), 1281-1287.

Stamatogiannakis, A., Chattopadhyay, A., \& Gorn, G. J. (Forthcoming). Can you fix it?: Effects of visual processing capacity on visual aesthetic response. Advances in Consumer Research.

Stevens, J. C., \& Patterson, M. Q. (1995). Dimensions of spatial acuity in the touch sense: Changes over the life span. Somatosensory and Motor Research, 12(1), 29-47.

Thornbury, J. M., \& Mistretta, C. M. (1981). Tactile sensitivity as a function of age. Journal of Gerontology, 36(1), 34-39.

Unnava, H. R., Agarwal, S., \& Haugtvedt, C. P. (1996). Interactive effects of presentation modality and message-generated imagery on recall of advertising information. Journal of Consumer Research, 23(1), 81-88.

Wansink, B., \& Van Ittersum, K. (2003). Bottoms up! The influence of elongation on pouring and consumption volume. Journal of Consumer Research, 30(3), 455-463.

Wrzesniewski, A., McCauley, C., \& Rozin, P. (1999). Odor and affect: Individual differences in the impact of odor on liking for places, things and people. Chemical Senses, 24(6), 713-721. 
Yalch, R. F., \& Spangenberg, E. R. (2000). The effects of music in a retail setting on real and perceived shopping times. Journal of Business Research, 49(2), 139-147.

Yorkston, E., \& Menon, G. (2004). A sound idea: Phonetic effects of brand names on consumer judgments. Journal of Consumer Research, 31(1), 43-51.

Zampini, M., \& Spence, C. (2004). The role of auditory cues in modulating the perceived crispness and staleness of potato chips. Journal of Sensory Studies, 19(5), 347-363.

Zelano, C., Bensafi, M., Porter, J., Mainland, J., Johnson, B., Bremner, E. et al. (2005). Attentional modulation in human primary olfactory cortex. Nature Neuroscience, 8(1), 114-120. 